\title{
Pregnancy outcome of a case with Swyer syndrome after bilateral gonadectomy and adjuvant chemotherapy
}

\author{
Cenk Gezer ${ }^{*}$, Atalay Ekin ${ }^{1}$, Alkim Gulsah Sahingoz Yildirim ${ }^{1}$, Ulas Solmaz ${ }^{2}$, Tugba \\ Karadeniz $^{3}$, Sevil Sayhan ${ }^{3}$, Mehmet Ozeren ${ }^{1}$
}

\begin{abstract}
Swyer syndrome is a rare disorder characterized by a phenotypic female with an XY karyotype. We presented a patient with Swyer syndrome with a diagnosis of malignant germ cell tumour. After bilateral gonadectomy and pelvic lymph node dissection, the patient received four courses of bleomycin, etoposide and cisplatin chemotherapy. The patient was free from tumour recurrence after 13years' follow-up. A successful pregnancy was achieved by oocyte donation and in vitro fertilization. Caesarean delivery was performed at 37 gestational weeks due to oligohydramnios and intrauterine growth restriction.
\end{abstract}

Key words: 46, XY gonadal dysgenesis; chemotherapy; gonadectomy; pregnancy; Swyer syndrome

\section{Introduction}

$\mathrm{XY}$ gonadal dysgenesis, known as Swyer syndrome, is a rare disorder characterized by phenotypically female with primary amenorrhea, tall stature, normal appearance of external genitalia, hypoplastic uterus, streak gonads and absence of secondary sex characteristics (1). Since gonads have no hormonal potential, diagnosis of this syndrome is usually made at adolescence. The current practice in Swyer syndrome is prompt removal of the dysgenetic gonads due to high risk of malignant tumour development. Furthermore, long-term combined oestrogen and progesterone therapy is recommended to induce puberty.

A number of successful pregnancies achieved by oocyte donation are described in the literature but cases with malignant germ cell tumours who received chemotherapy or radiotherapy have not been reported so far (2). Here, we report a successful pregnancy in a pure 46, XY gonadal dysgenetic woman with prior diagnosis of malignant germ cell tumour who underwent gonadectomy and received adjuvant chemotherapy.

\section{Case presentation}

A 17-year-old female was referred to our department for primary amenorrhea. Detailed examination and investigation for the cause of primary amenorrhea was performed. Patient was of a female phenotype with a $165 \mathrm{~cm}$ height and $55 \mathrm{~kg}$ in weight.
The secondary sexual characteristics including breast development and pubic hair were at Tanner stage III. Female external genitalia were present without evidence of cliteromegaly. The vagina was patent, and there was a small cervix. Pelvic ultrasonography revealed a small uterus $(5 \times 1.7 \times 2 \mathrm{~cm})$ and bilateral adnexal masses with the right side measuring $12 \times 12$ x $9 \mathrm{~cm}$ and left side measuring 10 x 11 x $8 \mathrm{~cm}$ (Fig. 1). Intravenous pyelography revealed normal urinary system anatomy and normal functioning kidneys accompanying a small bladder stone. Karyotype analysis demonstrated 46, XY genotype. Hormone levels revealed elevated serum follicle stimulating hormone $(65 \mathrm{mIU} / \mathrm{mL})$ and luteinizing hormone (24 $\mathrm{mIU} / \mathrm{mL}$ ) concentrations, a very low estradiol level (14 pg/mL), a normal total testosterone (23.02 ng/dL) and a low free testosterone level $(0.08 \mathrm{pg} / \mathrm{mL})$. Results implied primary gonadal failure in a phenotypic female with a male genotype. Tumour markers including CEA, $\beta$-hCG, CA-125, CA 19-9, CA 15-3 and AFP were within normal limits.

Laparotomy demonstrated a hypoplastic uterus, normally developed fallopian tubes and bilateral adnexal tumours, which confirmed our diagnosis of pure gonadal dysgenesis. There was no evidence of local or distant metastasis found during the operation. Bilateral gonadectomy and pelvic lymph node dissection were performed.

Received 07-06-2016 Accepted 26-06-2016 Available Online 15-07-2016

1 Dept of Perinatology, Izmir Tepecik Training and Research Hospital, Izmir, Turkey

2 Dept of Oncology, Izmir Tepecik Training and Research Hospital, Izmir, Turkey

3 Dept of Pathology, Izmir Tepecik Training and Research Hospital, Izmir, Turkey

* Corresponding Author: Cenk Gezer E-mail: drcenkgezer@gmailcom Phone: +90 2324330608 


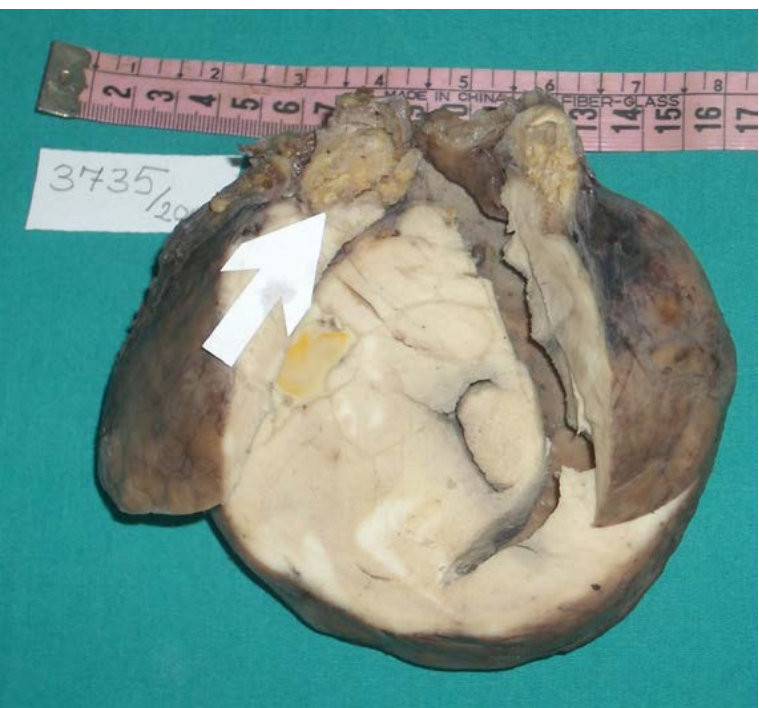

Figure 1: The gross appearance of left ovarian dysgerminoma arising from gonadoblastoma. Note the solid and lobulated surface of gonadoblastoma (white arrow).

Paraaortic lymph node dissection was not performed due to Pfannenstiel incision and existing controversies regarding optimal management of germ cell tumours at the time of surgery. Histopathologic examination documented gonadoblastoma on the right streak gonad and gonadoblastoma accompanied by dysgerminoma on the left gonad (Fig. 2). Dysgerminoma was spread beyond the ovarian capsule and lenfovascular space invasion was present. However, none of the lymph nodes showed a malignancy. After surgery, patient received four courses of adjuvant chemotherapy including bleomycin, etoposide and cisplatin. Cyclic oestrogen-progesterone therapy was also started. Postoperative period was uneventful and no recurrence was noted in the follow-up period. Thirteen years after initial diagnosis and at the age of 30 years she underwent in vitro fertilization with donated oocytes. Four fresh embryos were transferred and intrauterine presence of one live foetus noted at 6 weeks. Oestrogen and progesterone treatment was continued during the first trimester of pregnancy. Antenatal period was uneventful until 32 weeks of gestation, later on oligohydramnios has occurred with signs of foetal growth restriction. The Doppler analysis of umbilical and middle cerebral arteries was normal. Antenatal foetal surveillance with non-stress test and Doppler ultrasonography was continued every week until 37 gestational weeks and a healthy male neonate weighing 2460 gr was delivered by caesarean section. Both mother and neonate were discharged with no complications.

\section{Discussion}

Although Swyer syndrome was described in 1955, first successful pregnancy in a patient with this syndrome was reported about 20 years ago (3). Immense progress in the field of assisted reproduction techniques helps to obtain intact pregnancies in these patients. However, at present, the number of pregnancies with Swyer syndrome is too small to answer several questions regarding maintaining pregnancy and delivery.

Early diagnosis of the Swyer syndrome is crucial because of tumour transformation in the streak gonads and initiation of oestrogen therapy. Approximately 15 to $35 \%$ of females with pure gonadal dysgenesis develop gonadoblastoma (4). These are benign tumours arising from persisting undifferentiated gonadal tissue, which have no metastatic potential. The importance of this benign tumour is its potential to be the precursor of other germ cell malignancies such as dysgerminoma, embryonal carcinoma, yolk sac tumour and teratoma. Therefore, prompt surgical removal of dysgenetic gonads is advised after the diagnosis because the risk for malignant transformation increases with increasing age. In some cases, however, first manifestation of the disease can be the malignancy itself. Michala et al. reported that two of the 29 patients were first presented with malignancy before the diagnosis of XY gonadal dysgenesis (5). In our case, we performed bilateral gonadectomy to avoid future malignancies and also to preserve uterus in consideration of fertility. Continuous hormone treatment should be initiated following the diagnosis, especially if gonadectomy is performed. Supplementation of sexual hormones can induce regular menarche and also prevent osteoporosis.

Since women with Swyer syndrome do not produce germ cells, the only way to get pregnant is treatment with donor oocytes. Hormone treatment is needed to prepare the uterus for embryo implantation and should be continued during the first trimester of pregnancy. A few cases of successful pregnancies after oocyte donation and in vitro fertilization have been reported in the literature (6-13). When considering antenatal surveillance, patients with Swyer syndrome should be evaluated separately from patients having a 45,X cell line who are increased risk for aortic dissection and rupture during pregnancy (14). Although most of the pregnancies in women with Swyer syndrome were uneventful, some of them were complicated by unfavourable perinatal outcomes. Creatsas et al.(7), Kan et al.(8), Sauer et al.(9), and Ko et al.(10) observed hypertensive diseases in their cases with Swyer syndrome. 


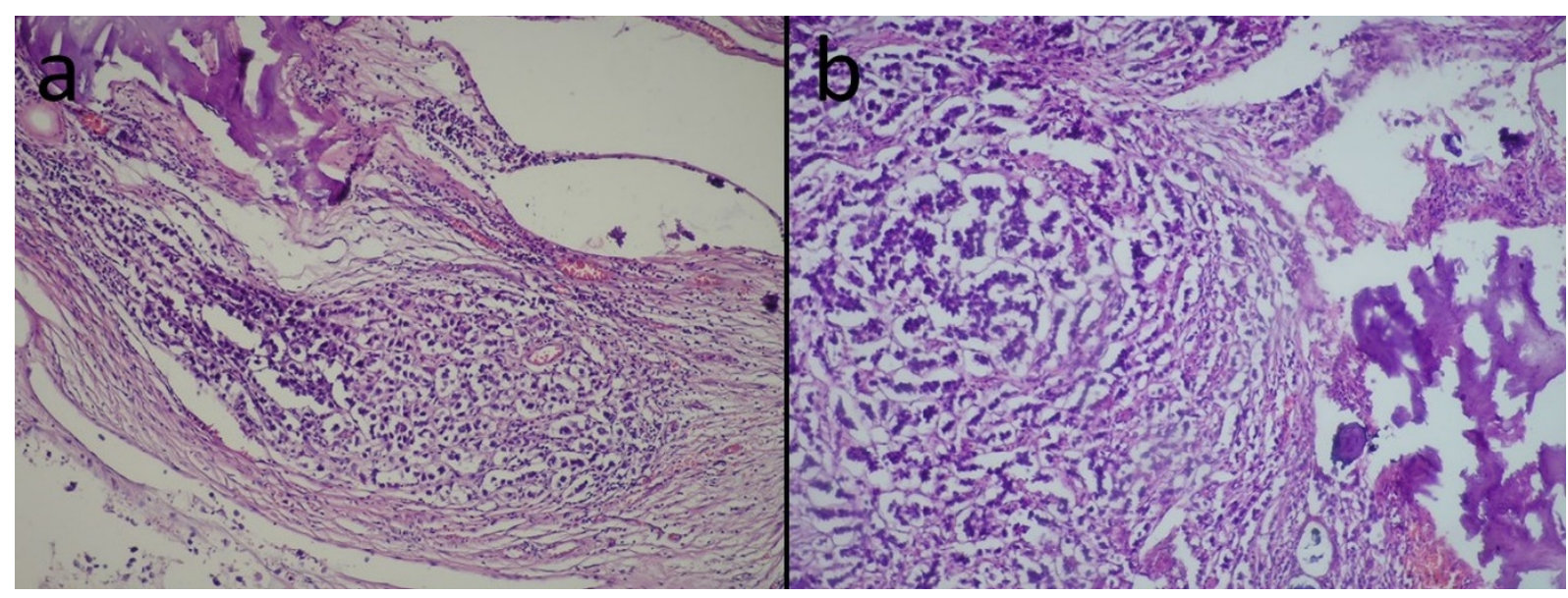

Figure 2: (a): Dysgerminoma is characterized by nests of round germ cells with vacuolated clear cytoplasm and large calcifications; Haematoxylin-eosin, x200 (b): Dysgerminoma consists of nests and cords of tumour cells and divided by occasional fibrous bands with lymphocytes; Haematoxylin-eosin, x100

Unlike others, Creatsas et al.(7), diagnosed blood pressure elevation in first trimester of pregnancy. Tulic et al.(11) reported reduced amniotic fluid at 39th week of gestation. Fedder et al.(12) presented a case of uterine rupture at 19 weeks of gestation in a patient with Swyer syndrome. They attributed this catastrophic event to the weakness of the uterine wall.

Preconceptional chemotherapy and radiotherapy is another (major) concern in women with malignant tumours and fertility desire. These adjuvant therapies found to be associated with increased preterm labour risk (15). None of the published reports of Swyer syndrome described a pregnancy after treatment with chemotherapy or radiotherapy for malignant germ cell tumours. Chen at al. reported a successful pregnancy in a patient with gonadoblastoma and accompanying mixed germ cell tumour but in their case they opted not to use adjuvant treatment because of aforementioned concerns (2). Our patient received four courses of bleomycin, etoposide and cisplatin therapy for treatment of dysgerminoma and any related side effects or any foetal anomaly was not observed. The only pathological event was the reduced amniotic fluid and late onset growth retardation without any other signs of foetal distress. In addition, no malignancy recurrence was noted in 13 years' of follow-up period

As in our case, caesarean section was chosen as the method of the delivery in most of the cases. One of the possible reasons for the relative high prevalence of caesarean delivery in patients with Swyer syndrome is the android shape of pelvis which may predispose them to abnormalities of labour. Another reason is that uterine size in $46, \mathrm{XY}$ patients tend to be smaller than the normal population (4). It is suggested that hormone receptors which react to prostaglandin and oxytocin may be deficient in hypoplastic uterus.
However, there is no evidence that vaginal delivery should be avoided. Siddique et al. and Michala et al. reported successful vaginal deliveries in their cases, suggesting that normal uterine function including vaginal delivery is possible in patients with Swyer syndrome $(5,13)$.

In summary, we presented the case of first known successful pregnancy achieved in a patient with Swyer syndrome after chemotherapy along with bilateral gonadectomy. Although achieving a pregnancy in the absence of ovaries is common in contemporary medicine, our case revealed the significance of conservative surgical management even in advanced stage diseases. It should be noted that increasing survival rates in patients affected by oncological disease and advances in reproductive medicine have led to the development and increasing use of various fertility preservation techniques.

Conflict of Interest: The authors declare no potential conflicts of interest with respect to the research, authorship, and/or publication of this article.

Ethical issues: All Authors declare that Originality of research/article etc... and ethical approval of research, and responsibilities of research against local ethics commission are under the Authors responsibilities. The study was completed due to defined rules by the Local Ethics Commission guidelines and audits.

Aknowledgement: Role of Authors: AE: Data collection, Manuscript writing/editing. AGSY: Manuscript writing/editing. US: Manuscript writing/editing. TK: Data collection, Data analysis. SS: Data collection, Data analysis. MO: Manuscript Editing 


\section{References}

1. Swyer GI. Male pseudohermaphroditism: a hitherto undescribed form. British medical journal. 1955 Sep 17;2(4941):709-12. PubMed PMID: 13250193. PMCID: 1980764.

2. Chen MJ, Yang JH, Mao TL, Ho HN, Yang YS. Successful pregnancy in a gonadectomized woman with 46,XY gonadal dysgenesis and gonadoblastoma. Fertility and sterility. 2005 Jul;84(1):217. PubMed PMID: 16009184.

3. Frydman R, Parneix I, Fries N, Testart J, Raymond JP, Bouchard P. Pregnancy in a 46, XY patient. Fertility and sterility. 1988 Nov;50(5):813-4. PubMed PMID: 3181493.

4. Hughes IA, Houk C, Ahmed SF, Lee PA, Group LC, Group EC. Consensus statement on management of intersex disorders. Archives of disease in childhood. 2006 Jul;91(7):554-63. PubMed PMID: 16624884. PMCID: 2082839.

5. Michala L, Goswami D, Creighton SM, Conway GS Swyer syndrome: presentation and outcomes. BJOG : an international journal of obstetrics and gynaecology. 2008 May;115(6):737-41. PubMed PMID: 18410658.

6. Dirnfeld M, Bider D, Abramovicia H, Calderon I, Blumenfeld Z. Subsequent successful pregnancy and delivery after intracytoplasmic sperm injection in a patient with XY gonadal dysgenesisms. European journal of obstetrics, gynecology, and reproductive biology. 2000 Jan;88(1):101-2. PubMed PMID: 10659926.

7. Creatsas G, Deligeoroglou E, Tsimaris P, Pantos K Kreatsa M. Successful pregnancy in a Swyer syndrome patient with preexisting hypertension. Fertility and sterility. 2011 Aug;96(2):e83-5. PubMed PMID: 21782051.

8. Kan AK, Abdalla HI, Oskarsson T. Two successful pregnancies in a 46,XY patient. Human reproduction. 1997 Jul;12(7):1434-5. PubMed PMID: 9262272.
9. Sauer MV, Lobo RA, Paulson RJ. Successful twin pregnancy after embryo donation to a patient with XY gonadal dysgenesis. American journal of obstetrics and gynecology. 1989 Aug;161(2):380-1. PubMed PMID: 2764056.

10. Ko PC, Peng HH, Soong YK, Chang SD. Triplet pregnancy complicated with one hydatidiform mole and preeclampsia in a $46, \mathrm{XY}$ female with gonadal dysgenesis. Taiwanese journal of obstetrics \& gynecology. 2007 Sep;46(3):276-80. PubMed PMID: 17962110.

11. Tulic I, Tulic L, Micic J. Pregnancy in patient with Swyer syndrome. Fertility and sterility. 2011 Apr;95(5):1789 e12. PubMed PMID: 21195397.

12. Fedder J, Ørskov M, Rubeck PK. Pregnancies in XY women: Is a weak myometrium cause of complications during pregnancy and delivery? . Asian Pac J Reprod 2013;2(1):76-9.

13. Siddique H, Daggett P, Artley K. Successful term vaginal delivery in a 46,XY woman. International journal of gynaecology and obstetrics: the official organ of the International Federation of Gynaecology and Obstetrics. 2008 Jun;101(3):298-9. PubMed PMID: 18280476.

14. Practice Committee of the American Society for Reproductive M. Increased maternal cardiovascular mortality associated with pregnancy in women with Turner syndrome. Fertility and sterility. 2006 Nov;86(5 Suppl 1):S127-8. PubMed PMID: 17055808.

15. Herrmann T, Thiede G, Trott KR, Voigtmann L. [Offsprings of preconceptionally irradiated parents. Final report of a longitudinal study 1976-1994 and recommendations for patients' advisory]. Strahlentherapie und Onkologie : Organ der Deutschen Rontgengesellschaft [et al]. 2004 Jan;180(1):21-30. PubMed PMID: 14704841. Nachkommen prakonzeptionell bestrahlter Eltern. Abschlussbericht einer Longitudinalstudie 1976-1994 und Empfehlungen zur Patientenberatung.

Copyright (C) 2016 The Author(s); This is an open-access article distributed under the terms of the Creative Commons Attribution License (http://creativecommons.org/licenses/by/4.0), which permits unrestricted use, distribution, and reproduction in any medium, provided the original work is properly cited. All Rights reserved by international journal of Medical Science and Discovery. 